Bulletin of Pharmaceutical Sciences
Assiut University
$\begin{gathered}\text { Website: http://lbpsa.journals.ekb.eg/ } \\ \text { e-mail: bullpharm@aun.edu.eg }\end{gathered}$

\title{
EVALUATION OF PHARMACOTHERAPY PROTOCOLS FOR COVID 19 PATIENTS IN BAQIYATALLAH HOSPITAL AND THEIR OUTCOMES
}

Hami Reza Ebrahimnegad ${ }^{1}$, Mahdi Mashhadi Akbar Boojar ${ }^{2,3}$, Abdol Majid Cheraghali ${ }^{2,3}$, Zeinab Shankayi ${ }^{4,5}$, Tahereh Mohammadzadeh ${ }^{6}$, Mohammad Hassan Mirasheh ${ }^{1}$, Mohammad Mahdi Poorhaji ${ }^{1}$, Mohammad Hosein Eidnezhad ${ }^{1}$, Maryam Shahriari ${ }^{1}$, Mohammad Mahdi Asadi $^{1}$, Hassan Amanpoor ${ }^{1}$, Mohammad Nikpouraghdam ${ }^{7}$ and Farideh Bahrami ${ }^{4,5^{*}}$

${ }^{1}$ Students' Research Committee, Baqiyatallah University of Medical Sciences, Tehran, Iran

${ }^{2}$ Department of Pharmacology and Toxicology, Faculty of Pharmacy, Baqiyatallah University of Medical Sciences, Tehran, Iran

${ }^{3}$ Chemical Injuries Research Center, Baqiyatallah University of Medical Sciences, Tehran, Iran

${ }^{4}$ Neuroscience Research Center, Baqiyatallah University of Medical Sciences, Tehran, Iran

${ }^{5}$ Department of Physiology and Medical Physics, School of Medicine, Baqiyatallah University of Medical Sciences, Tehran, Iran

${ }^{6}$ Health and Nutrition Research Center, Baghiyatallah Medical Sciences University, Tehran, Iran

${ }^{7}$ Nephrology and Urology Research Center, Baqiyatallah University of Medical Sciences, Tehran, Iran

Purpose: The propagation of the new coronavirus, COVID 19, is still a major priority for many countries around the world. Because of the lack of effective certain antiviral therapy for COVID 19. Special medicinal protocols are needed in medical centers to reduce the mortality rate. Methods: Due to constant change of national pharmacotherapy protocols for COVID-19 patients, this study compares the outcomes of three specific pharmacotherapy regimens (Table 1) and the combination of all 3 regimens for management of 614 COVID-19 patients hospitalized in Baqiyatallah hospital in Tehran, this hospital became a referral centers for receiving COVID 19 patients in Iran. Results: The more reliable result of treatments belongs to regimen 3 which indicated $98.26 \%$ recovered patients and $1.15 \%$ mortality rate and the lowest period of hospitalization with $4.4 \pm 0.21$ days' duration. Conclusion: It seems that regimen 3 (with a special combination of antiviral and Azithromycin ant anti-inflammatory drugs) had the best result in improving patients with COVID 19 and this result has not conflict with the comorbidity status of patients.

\section{INTRODUCTION}

Shortly after the WHO announcement of the first signs of the SARS-CoV-2 epidemic in the world on Dec. 31, 2019, the epidemic of new coronavirus quickly changed all aspects of people's lives around the world. Countries' health care system soon became involved with a pandemic infection of COVID-19. The virus infected millions worldwide and claimed several hundred thousand lives. Although some vaccines have been prepared they are not available with enough amounts in all countries and also the specific anti-viral drug has not been introduced to treat patients. Iran is among the countries badly hit by the epidemic ${ }^{1}$.

Received in 26/12/2020 \& Accepted in 31/1/2021 
Despite several months post epidemic control of COVID 19 propagation and still is a major priority for the world health and Economics ${ }^{2}$. The clinical manifestations of COVID 19 include a wide spectrum of illness from mild upper respiratory tract illness to severe respiratory failure and death (Cascella, 2020). This disease is usually clinically presented by fever, dry cough, dyspnea, fatigue, and nonprominent upper-respiratory-tract symptoms. In severe cases, septic shock, acute respiratory distress syndrome (ARDS), multiple organ dysfunction, and sudden death have been observed $^{3 \& 4}$.

Due to lack of sufficient vaccine and the financial problems which the countries may face with them for providing vaccines and besides of presence of some ambiguity about of immunity and efficacy of different kinds of vaccines, supportive care, and efficient medicinal protocol is a routine practice in medical centers to reduce mortality rate ${ }^{5}$. Despite substantial diversity in medical centers worldwide, current pharmacotherapy includes related and repurposed antiviral medicines and immunomodulating therapies including convalescent plasma therapy ${ }^{6-8}$.

In the early stage of the epidemic in Iran Baqiyatallah Hospital in Tehran became a referral center for receiving COVID 19 patients. The 12870 patients were referred to this hospital from February 19, 2020, to April 15, 2020, in which 2968 of them were hospitalized with a COVID-19 diagnosis. The majority of cases had 50 to 60 years old and the male-to-female ratio was 1.93:1. The Case Fatality Ratio was $1.85 \%$ based on the total number of patients and $8.06 \%$ among hospitalized patients. However, due to the constant change of national pharmacotherapy protocols for COVID-19, from February to April 2020 three major pharmacotherapy protocols have been used for the management of patients in this hospital. This study compares the outcomes of three specific pharmacotherapy regimens for the management of COVID-19 patients hospitalized in Baqiyatallah Hospital, Tehran, Iran.

\section{MATERIALS AND METHODS}

This study was approved by the institutional and research ethics board of Baqiyatallah University of Medical Sciences (IR.BMSU.REC.1399.142). This retrospective and the descriptive study included all adult patients $(\geq 24$ years old) registered as confirmed cases of COVID-19 using the RTPCR Diagnostic test. All patients were closed cases (died or discharged). A total of 614 were enrolled for this study. All of the demographic, epidemiological, clinical, and medicinal use data of patients were gathered using an electronic health information system (HIS).

Patients' drug profile was extracted from using data mining method. Patients received three major pharmacotherapy regimens recommended by the Iran Ministry of Health and the recommendations of the Baqiyatallah Hospital working group. Patients who have not received any of these three pharmacotherapy protocols for any reason have been excluded from the study.

Three common pharmacotherapy regimens were described in table 1.

Table 1: Three pharmacotherapy protocols used for management of COVID-19 patients.

\begin{tabular}{|l|l|}
\hline $\begin{array}{l}\text { Regimen 1 (twice } \\
\text { daily for 5 days) }\end{array}$ & $\begin{array}{l}\text { Oseltamivir Cap. 75 mg + Lopinavir/Ritonavir 400/100 mg Cap. + } \\
\text { Hydroxychloroquine 200 mg Tab. }\end{array}$ \\
\hline $\begin{array}{l}\text { Regimen 2 (for 5 } \\
\text { days) }\end{array}$ & $\begin{array}{l}\text { Prednisolone } 5 \mathrm{mg} \text { Tab. daily + Naproxen } 500 \mathrm{mg} \text { Tab. every 12 hrs + } \\
\text { Azithromycin 500 mg Tab. 1000 mg 1 }{ }^{\text {st }} \text { day, } 500 \mathrm{mg} / \text { day for 4 days }\end{array}$ \\
\hline & $\begin{array}{l}\text { Hydroxychloroquine } 200 \mathrm{mg} \text { Tab. every } 12 \mathrm{hrs}+\text { Azithromycin } 500 \mathrm{mg} \\
\text { Tab. } 1000 \mathrm{mg} 1^{\text {st }} \text { day, } 500 \mathrm{mg} / \text { day for 4 days + A nonsteroidal anti- } \\
\text { Regimen 3 (for 5 } \\
\text { iays) } \\
\text { steroidal anti-inflammatory drug (glucocorticoids; mainly } \\
\text { Prednisolone) }\end{array}$ \\
\hline
\end{tabular}


During the period presented in this study, patients received a total of 7 pharmacotherapy regimens including only regimen 1 , regimen 2 or regimen 3 , a combination of protocols 1 and 2 , regimen combination of protocols 1 and 3 , a combination of protocols 2 and 3, and finally the combination of all 3 regimens. In addition to antiviral therapy, patients may also receive other medicines for symptomatic relives of the sign of disease or their comorbidity.

Length of hospital staying and outcome (mortality or recovery) among patients who received different pharmacotherapy protocols were compared.

Most of the hospitalized patients had various diseases or underlying diseases, which could have had an influence on their final outcome, length of hospital stay, and the medications used. Therefore, in all these 7 groups, the correlation between comorbidity and pharmacotherapy regimen were examined.

\section{Statistical analysis}

The data were presented as MEN \pm SEM (standard error of means). The statistical analysis of one-way ANOVA was performed by using SPSS software (version 20) for comparing variables in the best protocols and comorbidities. The significance level was considered at a $\mathrm{P}$ value less than 0.05 .

\section{RESULTS AND DISCUSSION}

\section{Results}

Between 20 Feb. 2020 to 16 Apr. 2020, 620 confirmed COVID-19 patients who registered in Baqiyatallh Hospital included in the study. The epidemiological data of the patients were presented in table 2 . The mean age of the patients was $55 \pm 0.54$ years and $60.32 \%$ of them were male. The most common symptoms were fever, chills, shortness of breath, dry cough, fatigue, and myalgia (Table 3). Among these patients, 576 recovered and were discharged from the hospital, while 38 persons died (12.6\%).

Table 2: Demographic and underlying diseases of COVID-19 patients included in each medication regimen.

\begin{tabular}{|c|c|c|c|c|c|c|c|c|}
\hline \multirow{2}{*}{\multicolumn{2}{|c|}{ Variables }} & \multicolumn{7}{|c|}{ Pharmacotherapy Regimens } \\
\hline & & \multirow{2}{*}{$\begin{array}{c}\text { Regimen } \\
1 \\
53.57 \\
\pm 1.01\end{array}$} & \multirow{2}{*}{$\begin{array}{c}\text { Regimen } \\
2 \\
58.97 \\
\pm 2.03\end{array}$} & \multirow{2}{*}{$\begin{array}{c}\text { Regimen } \\
3 \\
53 \\
\pm 1.06\end{array}$} & \multirow{2}{*}{$\begin{array}{c}\text { Regimen } \\
1 \& 2\end{array}$} & \multirow{2}{*}{$\begin{array}{c}\text { Regimen } \\
1 \& 3\end{array}$} & \multirow{2}{*}{$\begin{array}{c}\text { Regimen } \\
2 \& 3 \\
55.88 \\
\pm 2.08\end{array}$} & \multirow{2}{*}{$\begin{array}{c}\begin{array}{c}\text { Regimen } \\
1 \& 2 \& 3\end{array} \\
59.33 \\
\pm 1.46\end{array}$} \\
\hline Age, year & $\begin{array}{l}\text { Mean } \\
\pm \text { SD }\end{array}$ & & & & & & & \\
\hline \multirow{2}{*}{$\begin{array}{c}\text { Gender, } \\
n(\%)\end{array}$} & Male & $\begin{array}{c}123 \\
(74.5)\end{array}$ & $\begin{array}{c}17 \\
(43.58)\end{array}$ & $\begin{array}{c}118 \\
(68.6)\end{array}$ & $\begin{array}{c}19 \\
(65.51)\end{array}$ & $\begin{array}{c}79 \\
(73.83)\end{array}$ & $\begin{array}{c}17 \\
(48.57)\end{array}$ & $\begin{array}{c}32 \\
(47.76)\end{array}$ \\
\hline & Female & $\begin{array}{c}41 \\
(25.5)\end{array}$ & $\begin{array}{c}22 \\
(56.41)\end{array}$ & $\begin{array}{c}54 \\
(31.39) \\
\end{array}$ & $\begin{array}{c}10 \\
(34.48) \\
\end{array}$ & $\begin{array}{c}28 \\
(26.16) \\
\end{array}$ & $\begin{array}{c}18 \\
(51.42) \\
\end{array}$ & $\begin{array}{c}35 \\
(52.23) \\
\end{array}$ \\
\hline \multirow{2}{*}{$\begin{array}{l}\text { Hyperten- } \\
\text { sion, } \\
n(\%)\end{array}$} & No & $\begin{array}{l}134.1 \\
(69.1)\end{array}$ & $\begin{array}{c}18 \\
(46.15)\end{array}$ & $\begin{array}{c}135 \\
(78.48)\end{array}$ & $\begin{array}{c}17 \\
(58.62)\end{array}$ & $\begin{array}{c}79 \\
(73.83)\end{array}$ & $\begin{array}{c}25 \\
(71.42)\end{array}$ & $\begin{array}{c}48 \\
(71.64)\end{array}$ \\
\hline & Yes & $\begin{array}{c}51 \\
(30.9)\end{array}$ & $\begin{array}{c}21 \\
(53.84)\end{array}$ & $\begin{array}{c}37 \\
(21.51)\end{array}$ & $\begin{array}{c}12 \\
(41.37)\end{array}$ & $\begin{array}{c}28 \\
(26.16) \\
\end{array}$ & $\begin{array}{c}10 \\
(28.57) \\
\end{array}$ & $\begin{array}{c}199 \\
(28.35) \\
\end{array}$ \\
\hline \multirow{2}{*}{$\begin{array}{c}\text { Diabetes, } \\
n(\%)\end{array}$} & No & $\begin{array}{c}116 \\
(70.3)\end{array}$ & $\begin{array}{c}24 \\
(61.53)\end{array}$ & $\begin{array}{c}128 \\
(74.41)\end{array}$ & $\begin{array}{c}24 \\
(82.75)\end{array}$ & $\begin{array}{c}80 \\
(74.76)\end{array}$ & $\begin{array}{c}29 \\
(82.85)\end{array}$ & $\begin{array}{c}56 \\
(83.85)\end{array}$ \\
\hline & Yes & $\begin{array}{c}49 \\
(29.69)\end{array}$ & $\begin{array}{c}15 \\
(38.46)\end{array}$ & $\begin{array}{c}44 \\
(25.58)\end{array}$ & $\begin{array}{c}5 \\
(17.24)\end{array}$ & $\begin{array}{c}27 \\
(25.23)\end{array}$ & $\begin{array}{c}6 \\
(17.14)\end{array}$ & $\begin{array}{c}11 \\
(16.41)\end{array}$ \\
\hline \multirow{2}{*}{$\begin{array}{c}\text { Lung } \\
\text { Disease, } \\
n(\%)\end{array}$} & No & $\begin{array}{c}154 \\
(93.3)\end{array}$ & $\begin{array}{c}36 \\
(92.3)\end{array}$ & $\begin{array}{c}151 \\
(87.79)\end{array}$ & $\begin{array}{c}14 \\
(48.27)\end{array}$ & $\begin{array}{c}92 \\
(85.98) \\
\end{array}$ & $\begin{array}{c}29 \\
(82.85)\end{array}$ & $\begin{array}{c}57 \\
(85.07)\end{array}$ \\
\hline & Yes & $\begin{array}{c}11 \\
(6.7)\end{array}$ & $\begin{array}{c}3 \\
(7.69)\end{array}$ & $\begin{array}{c}21 \\
(12.2)\end{array}$ & $\begin{array}{c}15 \\
(51.72) \\
\end{array}$ & $\begin{array}{c}15 \\
(14.01) \\
\end{array}$ & $\begin{array}{c}6 \\
(17.14) \\
\end{array}$ & $\begin{array}{c}10 \\
(14.92) \\
\end{array}$ \\
\hline
\end{tabular}


Table 3: Number of patients with clinical symptoms, the percent of patients has been shown in parenthesis.

\begin{tabular}{|l|c|}
\hline \multicolumn{1}{|c|}{ Symptoms } & $\begin{array}{c}\text { No. of patients } \\
(\%)\end{array}$ \\
\hline Fever (temperature $\geq 37 / 3)$ & $379(61.12)$ \\
\hline Dyspnea & $403(65.00)$ \\
\hline Dry cough & $331(53.38)$ \\
\hline Fatigue & $295(47.58)$ \\
\hline Myalgia & $292(47.09)$ \\
\hline Shivering & $310(50.00)$ \\
\hline Diarrhea & $100(16.12)$ \\
\hline Nausea or vomiting & $177(28.55)$ \\
\hline Chest pain & $170(27.42)$ \\
\hline Headache & $184(29.68)$ \\
\hline Sore throat & $70(11.29)$ \\
\hline Runny nose & $84(13.55)$ \\
\hline \hline
\end{tabular}

The general outline of the drugs used to treat and improve the symptoms of COVID 19 patients in supportive care during hospitalization is shown in table 1. The antiviral drugs Oseltamivir, Hydroxychloroquine, and Lopinavir/Ritonavir had the highest frequency in antiviral drugs. Broadspectrum antibacterial drugs were also used as soon as they were hospitalized to prevent widespread sepsis and secondary infection, and the distribution and frequency of these antibiotics are shown (Table 4). Levofloxacin, Meropenem, and Azithromycin were mostly used. The overall frequency of administered anti-inflammatory drugs was Steroidal or Nonsteroidal. Among NSAIDs, Naproxen had the highest recurrence $(23.68 \% *$ ), and among steroidal anti-inflammatory drugs or glucocorticoids, Inhaled Budesonide (42.34\%*), Prednisolone tablets $(34.22 \% *)$ and parenteral hydrocortisone $(5.57 \% *)$ had the most repetition.
Table 4: Frequency of antibiotics used as supportive treatment for COVID-19 patients.

\begin{tabular}{|l|c|}
\hline \multicolumn{1}{|c|}{ Antibiotic } & $\begin{array}{c}\text { Frequency of adminstration } \\
(\%)\end{array}$ \\
\hline Levofloxacin & $72.7 \%$ \\
\hline Meropenem & $69.22 \%$ \\
\hline $\begin{array}{l}\text { Azithromyci } \\
\mathrm{n}\end{array}$ & $63.76 \%$ \\
\hline Ceftriaxone & $32.4 \%$ \\
\hline Vancomycin & $21.37 \%$ \\
\hline Teicoplanin & $4.99 \%$ \\
\hline
\end{tabular}

Three typical regimens were considered in patients who were prescribed alone or in combination together to form a total of seven medications. The rate of administration and distribution of these regimens is shown in tables 2 and 5. Pharmacological regimens 1 and 3 and the combination of these two regimens were used in most patients. The combination of all three regimens (1, 2, and 3) was used mainly in elderly and critically ill patients admitted to the intensive care unit. In these patients, monotherapy often failed to improve the condition. The clinical outcome (mortality or recovery) and the length of hospitalization in each regimen are shown in table 5. It seems that regimen 3 had the best result in improving patients with COVID 19.

Because of the presence of comorbidity in some patients with Covid-19 the comorbid diseases of each case were identified. The percentage of patients involved with any of these diseases which have been treated by different regimen are shown in table 2 . Furthermore, the results of this study demonstrated that the reduction in hospitalization achieved by regimen 3 treatment was not affected by comorbid diseases of the patients (data are not shown). 
Table 5: Clinical Outcomes of pharmacotherapy regimns of COVID-19 patients presented as length of hospital stay, mortality and discharged from hospital.

\begin{tabular}{||l|c|c|c|c||}
\hline $\begin{array}{c}\text { Medication } \\
\text { protocol }\end{array}$ & $\begin{array}{c}\text { Total no. of } \\
\text { pateints }\end{array}$ & $\begin{array}{c}\text { No. of recovered } \\
\text { pateints }(\%)\end{array}$ & $\begin{array}{c}\text { No. of died } \\
\text { pateints }(\%)\end{array}$ & $\begin{array}{c}\text { Length of hospital saty } \\
\text { (days; Mean } \pm \text { SED) }\end{array}$ \\
\hline Regimen 1 & 165 & $149(90.3)$ & $14(8.48)$ & $5.92 \pm 0.23$ \\
\hline Regimen 2 & 39 & $37(94.87)$ & $2(5.12)$ & $6.21 \pm 0.38$ \\
\hline Regimen 3 & 173 & $170(98.26)^{*}$ & $3(1.15)^{*}$ & $4.41 \pm 0.21^{*}$ \\
\hline Regimen 1,2 & 29 & $28(98.55)$ & $1(3.44)$ & $6.46 \pm 0.62$ \\
\hline Regimen 1,3 & 108 & $102(97.11)$ & $6(2.88)$ & $6.42 \pm 0.43$ \\
\hline Regimen 2,3 & 35 & $29(82.85)$ & $6(17.14)$ & $6.82 \pm 0.63$ \\
\hline Regimen 1,2,3 & 67 & $61(91.04)$ & $6(8.95)$ & $9.12 \pm 0.59$ \\
\hline Total & 614 & 576 & 38 & 6.8 \\
\hline
\end{tabular}

\section{Discussion}

Pharmaceutical care of COVID 19 hospitalized patients is a prominent challenge worldwide. Although the new vaccines have been discovered as the Pfizer-BioNTech that it contains a small piece of the SARS-CoV-2 virus's mRNA which compel the cells in the body to make the virus's spike protein however the vaccination has not been completely spread around all of the countries in the word and also many countries are trying to prepare the other kind of vaccines. On the other hand, many patients have been reported that treated with antiviral drugs as lopinavir/ritonavir [which is widely used to treat HIV infection] in combination with the anti-flu drug oseltamivir, the remdesivir, which has been previously administered for Ebola virus treatment, have also proven effective against coronavirus. The antimalarial chloroquine and hydroxychloroquine, favipiravir were also reported as having anti-SARS-CoV-2 effects. Therefore, the conventional drugs seem continuously more reliable candidates for treating COVID 19 patients because knowledge on safety profile, dosing management, side effects, and drug interactions are well known ${ }^{9}$.

This retrospective analytical study has evaluated several common pharmacological regimens based on two indexes including the length of hospital stay and mortality rate for COVID19 patients. This study also compared clinical outcomes of drug regimens, focusing on 3 typical regimens that were applied in treating COVID 19 patients.

Patients receiving hydroxychloroquine, azithromycin, and an anti-inflammatory drug received better responses both in terms of reduced length of hospital stay and mortality than patients receiving hydroxychloroquine/ prednisolone or patients receiving oseltamivir, lopinavir, ritonavir, and hydroxychloroquine. Previous studies showed that a combination of hydroxychloroquine and azithromycin virologically treated all of the enrolled COVID 19 patients, compared with $57 \%$ cases treated with Hydroxychloroquine phosphate alone ${ }^{10 \& 11}$. However, prolongation of QT interval must be considered $^{12}$.

Data also revealed that using an antiretroviral regimen alone was not very effective and that taking anti-inflammatory drugs and azithromycin along with this antiretroviral regimen could make a significant improving effect on recovery rates and reduce the length of hospital stay.

The combination of all pharmacological regimens (1, 2, and 3) was used mainly in elderly and critically ill patients admitted to the intensive care unit. The host immune responses are responsible for producing life-threatening factors leading to ARDS in COVID 19 patients ${ }^{3}$. In these persons, single diets usually failed to improve the patient's condition, and the longest hospital stay and mortality were observed in this group ${ }^{3}$.

Finally, it was observed that hydroxychloroquine and an anti-inflammatory drug treatment regimen was able to improve and reduce the length of hospital stay with the least impact of underlying diseases (compared to people without the disease).

Current evidence demonstrated that host immune responses should be regarded as a life- 
threatening index leading to respiratory distress in COVID 19 patients $^{3}$. Hydroxychloroquine has a long-standing history in the treatment of chronic inflammatory diseases and has blocked viral entry into cells by suppressing glycosylation of host receptors ${ }^{13}$. It also has immunomodulatory effects by attenuation of cytokine production and lysosomal activity in host cells through interaction with membrane stability, cell signaling, and transcriptional activity $^{14-16}$

So far, there is no acceptable evidence for the efficacy of hydroxychloroquine treatment of SARS or MERS ${ }^{9}$. Some reports from China have stated that chloroquine was successfully applied to treat more than 100 COVID-19 patients resulting in improved para clinical findings, and reduced disease progression ${ }^{10}$. Combinations of direct mechanism and antiinflammatory and anti-coagulatory mechanisms perhaps by regulation iron hemostasis aid this drug to be a good choice for COVID-19 treatment ${ }^{16 \& 17}$.

Contrary to the present study, a recent investigation published in the journal of Lancet showed that co-administration of chloroquine and a macrolide not only did not have a considerable beneficial effect on the process of the disease but also increased the risk of dying from ventricular arrhythmias ${ }^{14}$.

Corticosteroids are generally have considered for attenuation of inflammatory responses and acute lung injuries and they were widely used for suppressing cytokine overflow and immune responses during the outbreak of SARS and MERS ${ }^{15 \& 18}$. However, this benefit may be accompanied by some adverse effects, including increased risk of secondary infection and postponed viral clearance ${ }^{19}$. Although the benefit of corticosteroids is unproven, reviews of outcomes are instructive in other viral types of pneumonia ${ }^{20}$. In contrast to patients with influenza-induced pneumonia which corticosteroid therapy was increased risk of mortality, investigations in patients with MERS and SARS demonstrated no relations of corticosteroids with improved survival ${ }^{15,21 \& 22}$. To some extent, similar to corticosteroids, the existing literature does not provide adequate evidence for the beneficial use of NSAIDs in the treatment of COVID-19 patients ${ }^{23}$.

Aline with these data it has been shown that azithromycin, more than an antimicrobial has significant antiviral properties. Its antiviral activity has been shown in many vitro and/or in-vivo studies. Moreover, the immunomodulation effects of azithromycin are the reason for its use in inflammatory lung disease. The azithromycin shows this property by inhibiting several cytokines involved in COVID-19 severe respiratory syndrome. It decreases the production of IL-1 $\beta$, IL-6, IL-8, IL-10, IL-12, and IFN- $\alpha^{24}$.

It was confirmed that in-vitro condition some antiretroviral therapy including Lopinavir/Ritonavir could be effective against other novel coronaviruses especially in the treatment of SARS by inhibition of viral proteases $^{25 \& 26}$. Some retrospective and observational studies in SARS have reported the reduction of mortality and intubation rates and they suggested that early administration of Lopinavir/Ritonavir during the peak of viral replication phase (first week of infection) is important on clinical outcomes ${ }^{27 \& 28}$. In accordance with our findings, a randomized controlled trial in 199 patients comparing the efficacy of Lopinavir/Ritonavir vs standard care demonstrated 2-points hospital discharge improvement on an ordinal scale ${ }^{29}$.

Before the discovery of SARS-CoV-2, because the initiation of COVID-19 in China occurred nearly during the outbreak of seasonal influenza, a large number of patients were treated with empirical oseltamivir therapy ${ }^{30}$. Currently, there is no acceptable evidence for in-vitro activity of oseltamivir against COVID 19 and some clinical trials conclude that oseltamivir has no role in the management of this infection ${ }^{9 \& 31}$.

Multidisciplinary and personalized management of hospitalized cases is very important to improve patient outcomes. Effective and logical pharmaceutical care, improving clinical outcomes, reducing mortality rate, and facilitating the pandemic control need to participate hospital pharmacists in the multidisciplinary teams.

In conclusion, this study demonstrated that the drug protocol consists of antiviral plus steroidal and nonsteroidal anti-inflammatory agents that in this study defined as regimen 3 was the proper treatment for recovering COVID 19 patients. By considering the importance of comorbidity and its impact on the clinical outcome of every regimen of 
treatment, the recovery effect of regimen 3 on covid-19 patients was independent of comorbidity of disease.

\section{Acknowledgments}

We kindly acknowledge the guidance and advice from the Clinical Research Development Units of Baqiyatallah Hospital and also thanks to the financial support of the Research Assistance office of Baqiyatallah University of Medical Sciences.

\section{REFERENCES}

1- Worldmeter. Coronavirus Cases_ Statistics and Charts - Worldometer [Accessed May 30, 2020.]. Available from: https://www.worldometers.info/ coronavirus/.

2- C. Wenham, J. Smith and R. Morgan, "COVID-19: The gendered impacts of the outbreak", The Lancet, 395, 846-848 (2020).

3- M. Cascella, M. Rajnik, A. Cuomo, S. C. Dulebohn and R. Di Napoli, "Features, Evaluation and Treatment Coronavirus (COVID-19)", StatPearls [internet], StatPearls Publishing (2020).

4- S. Kooraki, M. Hosseiny, L. Myers and A. Gholamrezanezhad, "Coronavirus (COVID-19) outbreak: What the department of radiology should know", Journal of the American College of Radiology, 17 (4), 447-451 (2020).

5- W-H. Chen, U. Strych, P. J. Hotez and M. E. Bottazzi, "The SARS-CoV-2 vaccine pipeline: An overview", Current Tropical Medicine Reports, 7 (12), 61-64 (2020).

6- A. Barlow, K. M. Landolf, B. Barlow, S. Y. A. Yeung, J. J. Heavner, C. W. Claassen, et al., "Review of emerging pharmacotherapy for the treatment of coronavirus disease 2019", Pharmacotherapy: The Journal of Human Pharmacology and Drug Therapy, 40, 416-437 (2020).

7- Z. Song, Y. Hu, S. Zheng, L. Yang and R. Zhao, "Hospital pharmacists' pharmaceutical care for hospitalized patients with COVID-19: Recommendations and guidance from clinical experience", Research in Social and Administrative Pharmacy, 17 (1), 20272031 (2021).
8- S. Yavuz and S. Ünal, "Antiviral treatment of COVID-19", Turkish Journal of Medical Sciences, 50, 611-619 (2020).

9- J. M. Sanders, M. L. Monogue, T. Z. Jodlowski and J. B. Cutrell, "Pharmacologic treatments for coronavirus disease 2019 (COVID-19): A review", Jama, 323, 1824-1836 (2020).

10- J. Gao, Z. Tian and X. Yang, "Breakthrough: Chloroquine phosphate has shown apparent efficacy in treatment of COVID-19 associated pneumonia in clinical studies", Bioscience Trends, 14 (1), 72-73 (2020).

11- P. Gautret, J-C. Lagier, P. Parola, L. Meddeb, M. Mailhe, B. Doudier, et al., "Hydroxychloroquine and azithromycin as a treatment of COVID-19: Results of an open-label non-randomized clinical trial", International Journal of Antimicrobial Agents, 56 (1), Article No. 105949 (2020).

12- E. Chorin, M. Dai, E. Shulman, L. Wadhwani, R. Bar-Cohen, C. Barbhaiya, et al., "The QT interval in patients with COVID-19 treated with hydroxychloroquine and azithromycin", Nature Medicine, 26 (6), 808-809 (2020).

13- A. Savarino, J. R. Boelaert, A. Cassone, G. Majori and R. Cauda, "Effects of chloroquine on viral infections: An old drug against today's diseases", The Lancet Infectious Diseases, 3, 722-727 (2003).

14- M. R. Mehra, S. S. Desai, F. Ruschitzka and A. N. Patel, "Hydroxychloroquine or chloroquine with or without a macrolide for treatment of COVID-19: A multinational registry analysis", The Lancet, 395, 1820 (2020).

15- Y. M. Arabi, Y. Mandourah, F. AlHameed, A. A. Sindi, G. A. Almekhlafi, M. A. Hussein, et al., "Corticosteroid therapy for critically ill patients with Middle East respiratory syndrome" American Journal of Respiratory and Critical Care Medicine, 197, 757-767 (2018).

16- E. Schrezenmeier and T. Dörner, "Mechanisms of action of hydroxychloroquine and chloroquine: Implications 
for rheumatology", Nature Reviews Rheumatology, 16, 155-166 (2020).

17- E. Q. Roldan, G. Biasiotto, P. Magro and I. Zanella, "The possible mechanisms of action of 4-aminoquinolines (chloroquine/ hydroxychloroquine) against Sars-Cov-2 infection (COVID-19): A role for iron homeostasis?", $\quad$ Pharmacological Research, 158, Article No. 104904 (2020).

18- B. Venkatesh, S. Finfer, J. Cohen, D. Rajbhandari, Y. Arabi, R. Bellomo, et al., "Adjunctive glucocorticoid therapy in patients with septic shock", New England Journal of Medicine, 378, 797-808 (2018).

19- T. Singhal, "A review of coronavirus disease-2019 (COVID-19)", The Indian Journal of Pediatrics, 87 (4), 281-286 (2020).

20- C. D. Russell, J. E. Millar and J. K. Baillie, "Clinical evidence does not support corticosteroid treatment for 2019nCoV lung injury", The Lancet, 395, 473475 (2020).

21- Y-N. Ni, G. Chen, J. Sun, B-M. Liang and Z-A. Liang, "The effect of corticosteroids on mortality of patients with influenza pneumonia: A systematic review and meta-analysis", Critical Care, 23 (1), Article No. 99 (2019).

22- L. J. Stockman, R. Bellamy and P. Garner, "SARS: Systematic review of treatment effects", PLoS Medicine, 3 (9), Article No. e343 (2006).

23- B. Russell, C. Moss, A. Rigg and M. Van Hemelrijck, "COVID-19 and treatment with NSAIDs and corticosteroids: Should we be limiting their use in the clinical setting?", Ecancermedicalscience, 14, Article No. 1023 (2020).

24- N. Bleyzac, S. Goutelle, L. Bourguignon and M. Tod, "Azithromycin for COVID19: More than just an antimicrobial?", Clinical Drug Investigation, 40 (8), 683686 (2020).
25- A. H. de Wilde, D. Jochmans, C. C. Posthuma, J. C. Zevenhoven-Dobbe, S. van Nieuwkoop, T. M. Bestebroer, et al., "Screening of an FDA-approved compound library identifies four smallmolecule inhibitors of Middle East respiratory syndrome coronavirus replication in cell culture", Antimicrobial Agents and Chemotherapy, 58, 48754884 (2014).

26- C. Chu, V. Cheng, I. Hung, M. Wong, K. Chan, K. Chan, et al., "Role of lopinavir/ritonavir in the treatment of SARS: Initial virological and clinical findings", Thorax, 59, 252-256 (2004).

27- T. T. Yao, J. D. Qian, W. Y. Zhu, Y. Wang and G. Q. Wang, "A systematic review of lopinavir therapy for SARS coronavirus and MERS coronavirus - A possible reference for coronavirus disease-19 treatment option", Journal of Medical Virology, 92, 556-563 (2020).

28- T. Que, V. Wong and K. Yuen, "Treatment of severe acute respiratory syndrome with lopinavir/ritonavir: A multicentre retrospective matched cohort study", Hong Kong Med. J., 9, 399-406 (2003).

29- B. Cao, Y. Wang, D. Wen, W. Liu, J. Wang, G. Fan, et al., "A trial of lopinavirritonavir in adults hospitalized with severe Covid-19", New England Journal of Medicine, 382 (19), 1787-1799 (2020).

30- D. Wang, B. Hu, C. Hu, F. Zhu, X. Liu, J. Zhang, et al., "Clinical characteristics of 138 hospitalized patients with 2019 novel coronavirus-infected pneumonia in Wuhan, China", Jama, 323, 1061-1069 (2020).

31- Ö. Kutlu and A. Metin, "A case of exacerbation of psoriasis after oseltamivir and hydroxychloroquine in a patient with COVID-19: Will cases of psoriasis increase after COVID-19 pandemic?", Dermatologic Therapy, 33 (4), Article No. e13383 (2020). 


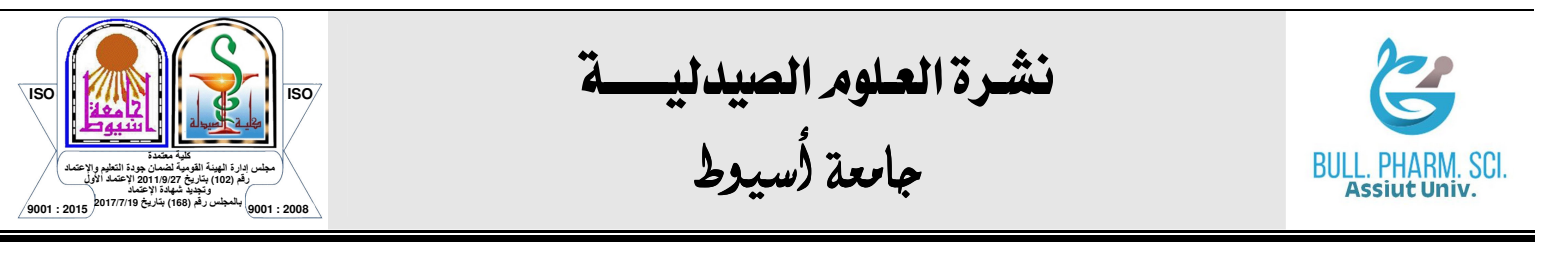

\section{تقييم بروتوكولات العلاج الدوائي لمرضى كوفيد 9 ألمانه ونتائجها في

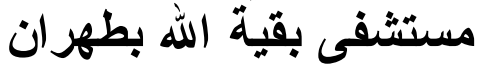

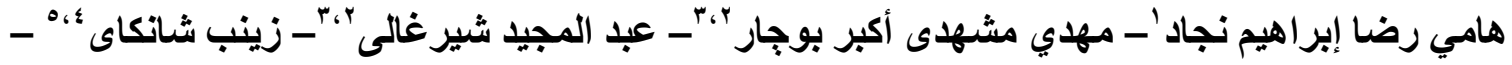

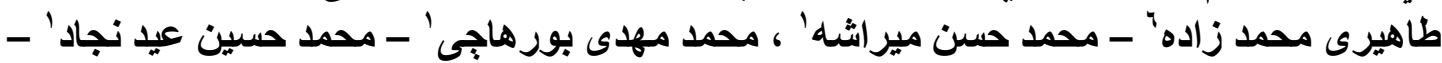

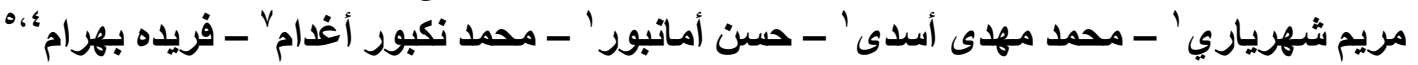

' لجنة أبحاث الطلاب ، جامعة بقية الله للعلوم الطبية ، طهران ، إيران

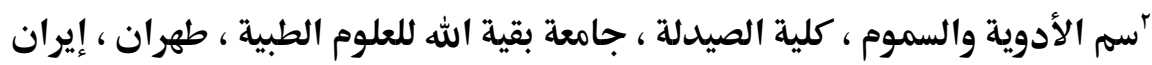

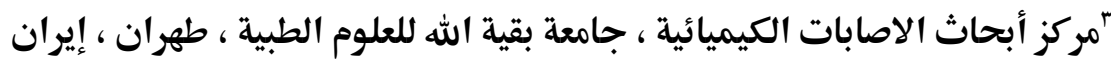

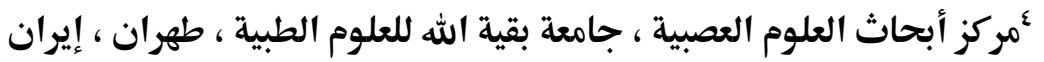

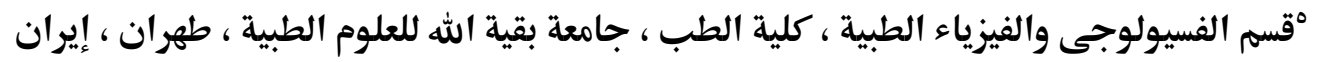

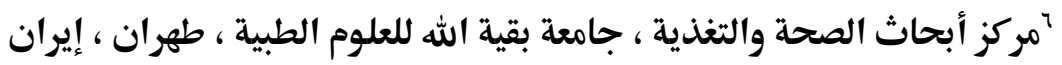

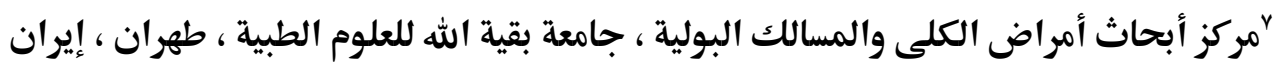

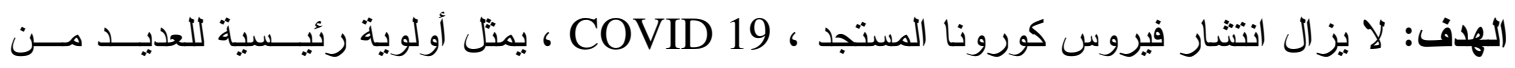

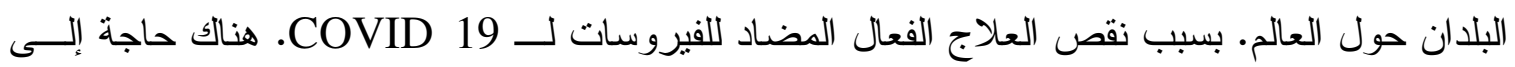
بروتوكو لات طبية خاصة في المر اكز الطبية لتقليل معدل الوفيات.

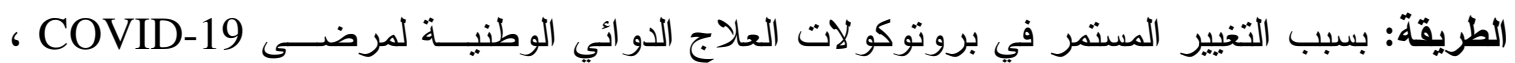

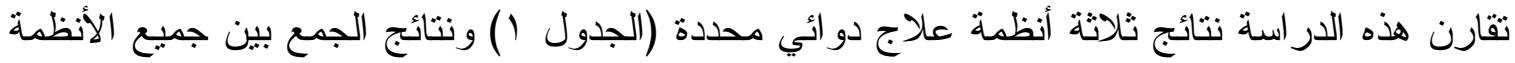

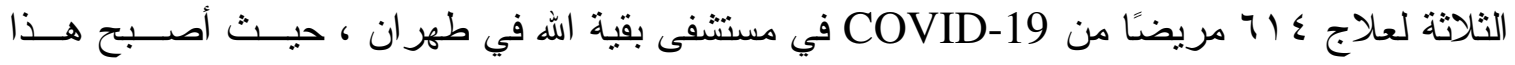
المستشفى مركز إحالة لاستقبال مرضى 19 COVID 19 في إيران.

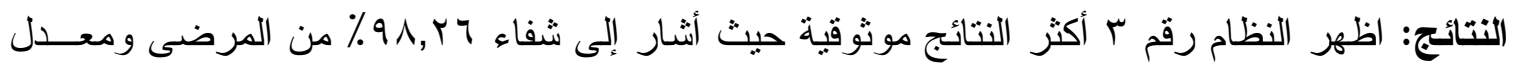

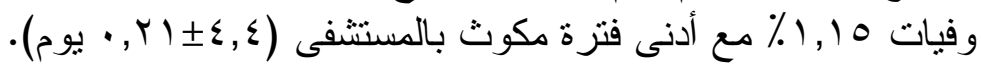

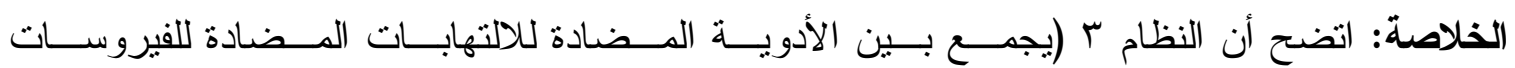

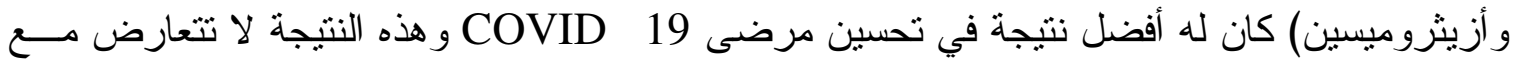

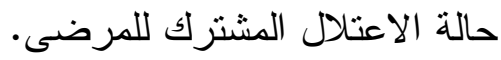

